\title{
The Circulatory Effects of Electrically Induced Changes in Ventricular Rate at Rest and during Exercise in Complete Heart Block *
}

\author{
N. Segel, W. A. Hudson, P. Harris, and J. M. Bishop \\ (From the Department of Medicine, University of Birmingham, Queen Elizabeth Hospital, \\ Birmingham, England)
}

Measurements of the cardiac output in patients with congenital heart block were first made by indirect methods $(1,2)$, and later in a few patients by right heart catheterization at rest (3-5) and during exercise (6). These studies showed that the stroke volume was large and the cardiac output and pulmonary arterial and wedge pressures were normal at rest $(3,4)$ and during exercise (6). The rise in cardiac output during exercise was achieved mainly by the increase in ventricular rate which is characteristic of the congenital, but not the acquired, form of heart block $(6,7)$.

The acquired differs from the congenital form in that it occurs in an older age group, has a poorer prognosis, is often associated with underlying myocardial damage, and sometimes with congestive cardiac failure (7-9). The ventricular rate is lower at rest and generally remains unchanged or increases only slightly with exercise (7). In the first few patients studied in our laboratory $(10,11)$, the cardiac output at rest and during exercise was abnormally low and the pulmonary arterial and wedge pressures were high.

With the introduction of electrical pacemakers for use in heart block (12-15), it became important to determine the effects of the increase in heart rate and to define the optimal rates at which to stimulate the heart. Some observations concerning the latter have been reported in preliminary communications $(16,11)$ and in two patients with implanted myocardial electrodes (17). In the present investigation we have studied the influence of complete atrioventricular (A-V) block upon the systemic and pulmonary circulations at

* Submitted for publication September 12, 1963 ; accepted March 26, 1964.

Supported in part by the Endowment Research Fund of the United Birmingham Hospitals. rest and during exercise and also the effects of changes in heart rate induced by an artificial pacemaker in the right ventricle.

\section{Methods}

Patients. Fourteen patients with complete A-V block were studied, and details of their physical characteristics are given in Table I. The heart block was congenital in one patient (Patient 1) and was acquired in the rest. In four of these (Patients 4, 9, 11, and 12) there was a history of, or electrocardiographic changes to suggest, underlying ischemic heart disease. Patient 7 had had diphtheritic myocarditis 7 years before the onset of heart block, but in the remaining eight patients the etiology was obscure, there being no history of cardiac pain or rheumatic fever and no associated valve disease or hypertension. Patients 6 and 14 were in congestive heart failure at the time of study. The site of the idioventricular pacemaker as judged by the duration and form of the QRS complex was in the bundle of His in four patients (Patients $1,6,10,12$ ), in the right ventricle in three (Patients 8, 9, and 14), and in the left ventricle in the rest. One patient was in atrial fibrillation (Patient 12), and three patients (Patients 8,12, and 14) were taking digoxin and chlorothiazide at the time of study. All the patients with acquired heart block were admitted to hospital because of uncontrolled Stokes-Adams attacks or heart failure.

Procedure. Arterial pressure was measured through an indwelling needle in the brachial artery. A doublelumen catheter was advanced into the lung so that its tip was wedged into a peripheral pulmonary artery while the proximal orifice lay in the pulmonary arterial trunk or one of its main branches.

The intravascular pressures were measured by capacitance manometers and recorded by a multichannel direct-writing instrument. The zero reference level for pressures was $10 \mathrm{~cm}$ above the plane of the catheterization table. Mean pressures were determined by planimetry, and all pressures were averaged over at least three respiratory cycles.

The cardiac output was measured by the direct Fick method. Expired gas was collected in a Tissot spirometer over a period of 3 minutes during which two samples each of arterial and mixed venous blood were taken 


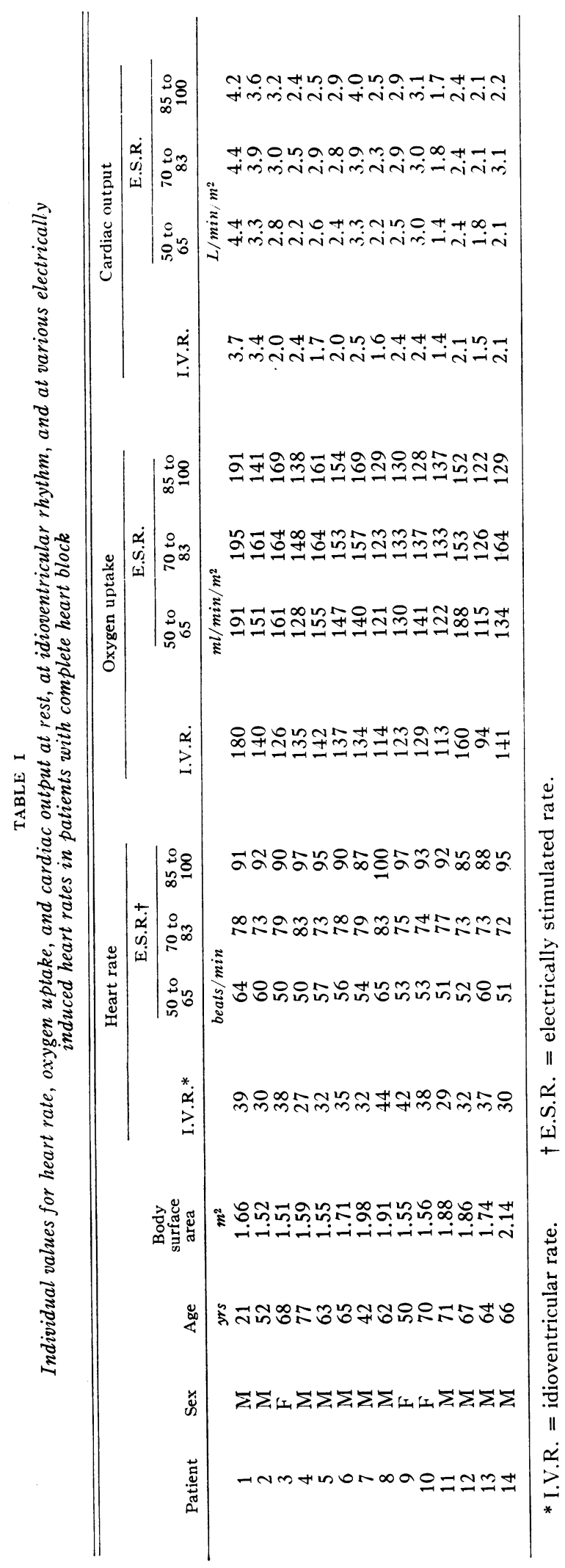

for the determination of the percentage of oxygen saturation (18). The blood oxygen capacity was determined photometrically, a sample being taken during each estimation of the cardiac output. Expired gas was analyzed in a Scholander apparatus. Pulmonary vascular resistance was calculated by the usual method (19).

Direct endocardial stimulation was carried out via a no. 6 catheter electrode inserted into the right ventricle. The external end of the catheter electrode was attached to a square wave generator that delivered a 5 millisecond pulse, dischargeable from 0 to $9 \mathrm{v}$ at a rate that could be varied between 40 and 150 pulses per minute (10). The indifferent lead of the pacemaker was connected to a skin plate electrode of the type used for electrocardiograms, placed in the left pectoral region. The catheter electrode was inserted at the beginning of the procedure, the most sensitive site for achieving adequate myocardial response being the apical region of the right ventricle. The electrocardiogram was displayed on a cathode ray oscilloscope throughout the whole period of study.

Each patient was studied at rest in the supine position, without sedation, 6 hours after a light meal. Twelve patients were also studied during exercise. In each study the cardiac output and intravascular pressures were measured at the patient's idioventricular rate and during varying electrically stimulated heart rates ranging between 50 and 100 beats per minute. Cardiac output was measured once at idioventricular rate and then at the end of three separate 20-minute periods. In half of the patients the ventricular rate was artificially increased at the beginning of each period. In the other half the order of study was reversed so that the cardiac output was measured first during the highest ventricular rate and then at progressively decreasing rates until the pulse generator was switched off and a final measurement was made at idioventricular rate. Intravascular pressures were measured immediately before and after each estimate of cardiac output.

The patients then performed light exercise at a steady rate on a bicycle ergometer for 6 minutes. Cardiac output was measured during the fourth minute, and intravascular pressures were recorded during the third and fifth minutes of exercise. Each patient exercised twice with a 20 -minute period of rest in between: once at their own idioventricular rate and once during an electrically stimulated ventricular rate ranging from 73 to 94 beats per minute. The order of study was also reversed in half of the group.

On completion of the study the catheter electrode was left in place in many patients for continued control of the heart rate until an inductive-coupled coil pacemaker was implanted (10).

\section{Results}

Tables I and II show the individual values at rest for cardiac output, oxygen uptake, and intravascular pressures at idioventricular and varying 
artificially stimulated ventricular rates. The corresponding measurements during exercise are given in Tables V and VI. The mean values for these and other related measurements at rest and during exercise are given in Table III. The figures for heart rate and intravascular pressures represent the average of two measurements made immediately before and after each cardiac output.

Observations at rest at idioventricular rate (Tables $I, I I$, and $I I I)$

The individual values for oxygen uptake, cardiac output, stroke volume, and pulmonary arterial mean and wedge pressures are illustrated in Figure 1 , and the average values are given in Table III.

The average cardiac output was significantly lower $(t=4.33, \mathrm{p}<0.001)$ and the stroke volume significantly higher $(t=4.06, \mathrm{p}<0.001)$ than the average values obtained by a dye dilution method in ten normal elderly subjects (20). The oxygen uptake was not greatly different from the average values reported by Granath, Jonsson, and Strandell (21).

Since age does not affect the pulmonary arterial and wedge pressures (21), the results for these measurements have been compared to the observations made in our own series of normal subjects studied under similar conditions, the mean values for which are shown in Table IV. Both the pulmonary arterial and wedge pressures were significantly higher $(t=10.30,10.12, \mathrm{p}<0.001)$ as was the pulmonary vascular resistance $(t=$ 3.39, $\mathrm{p}<0.01$ ).

\section{Effects of increasing ventricular rate at rest ( $T a$ -} bles $I, I I$, and $I I I$ )

The average values for the systemic and pulmonary intravascular pressures and cardiac output at varying heart rates from idioventricular rate to 100 beats per minute are shown in Figure 2 .

Although there was some individual variation, on the average the cardiac output increased with the heart rate and reached its highest level between 70 and 83 beats per minute when it was restored to normal $(20,21)$. Further increments in heart rate produced no substantial rise in cardiac output, and in six patients there was a fall. In five patients the cardiac output increased by 0.1 to $0.2 \mathrm{~L}$

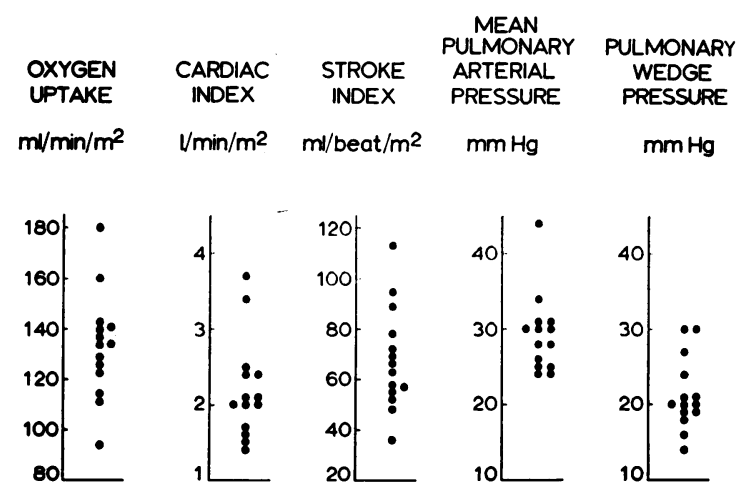

Fig. 1. InDIVIDUAL VALUES FOR OXYGEN UPTAKe, CARDIAC OUTPUT, AND PULMONARY ARTERIAL MEAN AND WEDGE PRESSURES IN PATIENTS WITH COMPLETE HEART BLOCK AT REST AT IDIOVENTRICULAR RATE.

per minute per $\mathrm{m}^{2}$, and in three there was no change. The cardiac output at rates of 70 to 83 beats per minute was significantly greater than that at idioventricular rhythm $(t=5.52, \mathrm{p}<$ 0.001 ) and at 50 to 65 beats per minute ( $t=$ 2.86, $\mathrm{p}<0.02$ ) but was not essentially different from that at 85 to 100 beats per minute ( $t=$ $0.79, \mathrm{p}<0.10)$. The stroke volume fell with each increment in heart rate from a mean of 65 $\mathrm{ml}$ per $\mathrm{m}^{2}$ at idioventricular rate to $31 \mathrm{ml}$ per $\mathrm{m}^{2}$
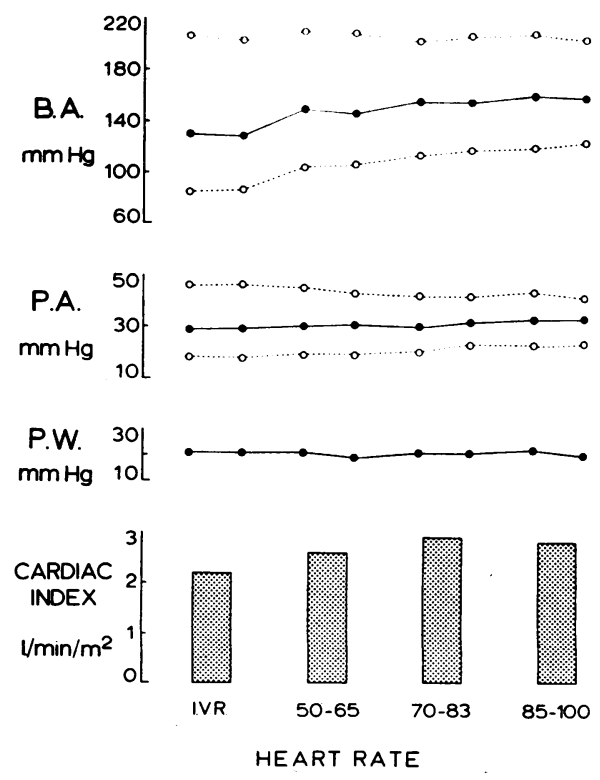

Fig. 2. Mean values at Rest for brachial arterial (B.A.), PUlmonary arterial (P.A.), AND WEdGe PRESSURES (P.W.) AND CARDIAC OUTPUT AT IDIOVENTRICULAR RATE (I.V.R.) AND ELECTRICALLY STIMULATED HEART RATES IN 14 PATIENTS WITH COMPLETE HEART BLOCK. 
TABLE II

Individual values for brachial and pulmonary arterial and pulmonary wedge

\begin{tabular}{|c|c|c|c|c|c|c|c|c|c|c|c|c|c|c|}
\hline \multirow[b]{3}{*}{ Patient } & \multicolumn{7}{|c|}{$\begin{array}{l}\text { Idioventricular rate } \\
\text { Pressure }\end{array}$} & \multicolumn{7}{|c|}{$\begin{array}{c}\text { Heart rate, } 50 \text { to } 65 \text { beats } / \mathrm{min} \\
\text { Pressure }\end{array}$} \\
\hline & \multicolumn{3}{|c|}{$\begin{array}{l}\text { Brachial } \\
\text { arterial }\end{array}$} & \multicolumn{3}{|c|}{$\begin{array}{l}\text { Pulmonary } \\
\text { arterial }\end{array}$} & \multirow{2}{*}{$\begin{array}{c}\text { Pulmonary } \\
\text { wedge } \\
\text { M }\end{array}$} & \multicolumn{3}{|c|}{$\begin{array}{l}\text { Brachial } \\
\text { arterial }\end{array}$} & \multicolumn{3}{|c|}{$\begin{array}{l}\text { Pulmonary } \\
\text { arterial }\end{array}$} & \multirow{2}{*}{$\begin{array}{c}\text { Pulmonary } \\
\text { wedge } \\
\text { M }\end{array}$} \\
\hline & $\mathrm{S}^{*}$ & I) & $\bar{M}$ & $s$ & $\mathrm{D}$ & $\bar{M}$ & & $\mathrm{~S}$ & $\mathrm{D}$ & $\mathbf{M}$ & $\mathrm{S}$ & $\mathrm{D}$ & $\mathbf{M}$ & \\
\hline & \multicolumn{7}{|c|}{$m m \mathrm{Hg}$} & \multicolumn{7}{|c|}{$m m H g$} \\
\hline 1 & 184 & 96 & 128 & 41 & 15 & 28 & 20 & 187 & 103 & 136 & 37 & 16 & 26 & 16 \\
\hline 2 & 189 & 70 & 107 & 40 & 17 & 24 & 20 & 207 & 96 & 137 & 40 & 16 & 31 & 19 \\
\hline 3 & 201 & 78 & 119 & 42 & 15 & 25 & 19 & 205 & 86 & 132 & 4.3 & 17 & 27 & 22 \\
\hline 4 & 239 & 91 & 148 & 41 & 11 & 28 & 14 & 230 & 121 & 158 & 33 & 14 & 23 & 17 \\
\hline 5 & 209 & 68 & 125 & 42 & 16 & 30 & 20 & 214 & 90 & 150 & 38 & 18 & 28 & 17 \\
\hline 6 & 260 & 98 & 180 & 67 & 30 & 44 & 30 & 258 & 123 & 191 & 60 & 30 & 43 & 30 \\
\hline 7 & 187 & 90 & 124 & 39 & 13 & 24 & 16 & 179 & 115 & 139 & 38 & 17 & 27 & 19 \\
\hline 8 & 137 & 64 & 92 & 48 & 20 & 31 & 20 & 200 & 113 & 149 & 48 & 24 & 34 & 22 \\
\hline 9 & 188 & 92 & 130 & 47 & 19 & 30 & 24 & 194 & 101 & 138 & 47 & 19 & 31 & 18 \\
\hline 10 & 228 & 78 & 127 & 42 & 19 & 26 & 19 & 240 & 107 & 159 & 42 & 16 & 25 & 18 \\
\hline 11 & 226 & 88 & 127 & 39 & 16 & 25 & 20 & 229 & 110 & 148 & 39 & 20 & 26 & 24 \\
\hline 12 & 207 & 83 & 117 & 54 & 23 & 31 & 27 & 196 & 89 & 131 & 56 & 21 & 32 & 20 \\
\hline 13 & 199 & 106 & 148 & 51 & 18 & 30 & 18 & 185 & 109 & 141 & 42 & 17 & 26 & 14 \\
\hline 14 & 198 & 88 & 132 & 52 & 18 & 34 & 30 & 194 & 104 & 151 & 54 & 21 & 39 & 28 \\
\hline
\end{tabular}

$* \mathrm{~S}=$ systolic, $\mathrm{D}=$ diastolic, and $\mathrm{M}=$ mean.

at a rate between 85 and 100 beats per minute. The variation in stroke volume between the different rates was significant (analysis of variance, $\mathrm{p}<0.001$ ).

The oxygen uptake continued to rise as the heart rate increased, reaching a maximal value between 70 and 83 beats per minute. The variation in oxygen uptake between the different heart rates was significant (analysis of variance, $\mathrm{p}<$ 0.001 ). The expired volume and respiratory exchange ratio varied little during the changes in

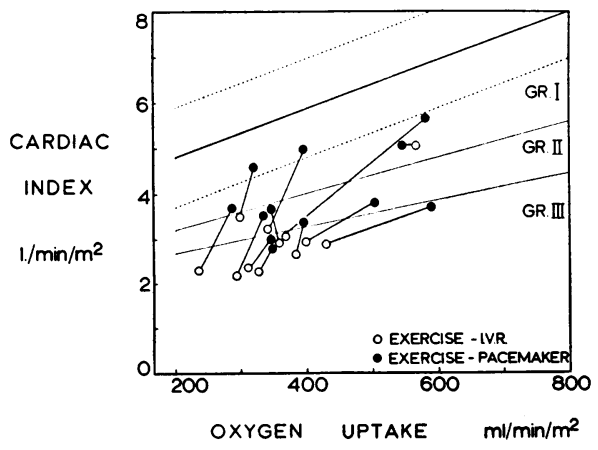

Fig. 3. Individual values for CARdiac OUtPut Plotted AGAINST OXYGEN UPTAKE DURING EXERCISE AT IDIOVENTRICULAR (I.V.R.) AND ELECTRICALLY STIMULATED HEART RATES (PACEMAKER). The regression line and $95 \%$ confidence limits of cardiac output on oxygen uptake in normal subjects during exercise (24), and three arbitrary grades of impairment of the response of cardiac output to exercise (22), are shown. ventricular rate (Table III). The a-v oxygen difference fell with each increment in heart rate, reaching its lowest level between 70 and 83 beats per minute (Table III), when it was significantly different from the value at idioventricular rate $(t=4.08, \mathrm{p}<0.001)$ and at 50 to 65 beats per minute $(t=2.99, \mathrm{p}<0.02)$.

The brachial and pulmonary arterial mean and diastolic pressures rose with an increasing heart rate, but the average systolic pressure changed little. The pulmonary wedge pressure was essentially unaffected by the changes in heart rate, and the pulmonary vascular resistance remained unaltered.

\section{Observations during exercise (Tables $I I I, V$, and $V I)$}

The individual values for cardiac output and oxygen uptake during exercise at both idioventricular and electrically stimulated heart rates are shown in Figure 3.

Exercise at idioventricular rate. The exercise performed by this group was very light, since most were unable to do more, and the mean oxygen uptake during the fourth minute of exercise was only $354 \mathrm{ml}$ per minute per $\mathrm{m}^{2}$. The average cardiac output increased significantly from the average resting value of $2.2 \mathrm{~L}$ per minute per $\mathrm{m}^{2}$ to $3.0 \mathrm{~L}$ per minute per $\mathrm{m}^{2}(t=5.50, \mathrm{p}<0.001)$. The mean a-v oxygen difference rose from the 
TABLE II

pressures at rest and at various heart rates in patients with complete heart block

\begin{tabular}{|c|c|c|c|c|c|c|c|c|c|c|c|c|c|}
\hline \multicolumn{7}{|c|}{$\begin{array}{c}\text { Heart rate, } 70 \text { to } 83 \text { beats } / \mathrm{min} \\
\text { Pressure }\end{array}$} & \multicolumn{7}{|c|}{$\begin{array}{c}\text { Heart rate, } 85 \text { to } 100 \text { beats } / \mathrm{min} \\
\text { Pressure }\end{array}$} \\
\hline \multicolumn{3}{|c|}{$\begin{array}{l}\text { Brachial } \\
\text { arterial }\end{array}$} & \multicolumn{3}{|c|}{$\begin{array}{l}\text { Pulmonary } \\
\text { arterial }\end{array}$} & \multirow{2}{*}{$\begin{array}{l}\text { Pulmonary } \\
\text { wedge } \\
\mathbf{M}\end{array}$} & \multicolumn{3}{|c|}{$\begin{array}{l}\text { Brachial } \\
\text { arterial }\end{array}$} & \multicolumn{3}{|c|}{$\begin{array}{l}\text { Pulmonary } \\
\text { arterial }\end{array}$} & \multirow{2}{*}{$\begin{array}{l}\text { Pulmonary } \\
\text { wedge } \\
\text { M }\end{array}$} \\
\hline $\mathbf{S}$ & D & $\mathbf{M}$ & $\mathbf{S}$ & D & $\mathbf{M}$ & & $\mathrm{S}$ & D & $\mathbf{M}$ & $\mathrm{S}$ & D & $\mathbf{M}$ & \\
\hline \multicolumn{7}{|c|}{$m m \mathrm{Hg}$} & \multicolumn{7}{|c|}{$m m H g$} \\
\hline 188 & 116 & 139 & 35 & 18 & 26 & 13 & 204 & 130 & 155 & 42 & 25 & 33 & 16 \\
\hline 200 & 100 & 139 & 39 & 16 & 27. & 23 & 203 & 106 & 149 & 43 & 14 & 31 & 21 \\
\hline 212 & 114 & 159 & 54 & 23 & 40 & 33 & 215 & 114 & 161 & 48 & 28 & 38 & 26 \\
\hline 220 & 129 & 181 & 40 & 24 & 31 & 20 & 242 & 152 & 193 & 46 & 29 & 36 & 26 \\
\hline 197 & 94 & 143 & 35 & 17 & 25 & 16 & 200 & 105 & 150 & 38 & 19 & 28 & 16 \\
\hline 249 & 138 & 194 & 52 & 31 & 41 & 31 & 248 & 150 & 206 & 49 & 29 & 39 & 29 \\
\hline 172 & 110 & 139 & 40 & 20 & 31 & 19 & 176 & 112 & 140 & 42 & 24 & 34 & 23 \\
\hline 194 & 117 & 145 & 47 & 24 & 34 & 20 & 198 & 117 & 151 & 47 & 27 & 35 & 21 \\
\hline 196 & 116 & 150 & 46 & 25 & 35 & 20 & 190 & 118 & 150 & 44 & 27 & 34 & 20 \\
\hline 230 & 122 & 168 & 39 & 19 & 27 & 19 & 230 & 129 & 171 & 36 & 19 & 25 & 14 \\
\hline 235 & 135 & 169 & 39 & 21 & 29 & 22 & 241 & 145 & 181 & 44 & 24 & 34 & 27 \\
\hline 198 & 112 & 145 & 43 & 19 & 28 & 17 & 189 & 117 & 140 & 47 & 22 & 28 & 16 \\
\hline 176 & 108 & 139 & 38 & 17 & 27 & 14 & 167 & 105 & 134 & 34 & 18 & 26 & 13 \\
\hline 190 & 106 & 156 & 42 & 16 & 30 & 20 & 186 & 108 & 148 & 55 & 22 & 40 & 31 \\
\hline
\end{tabular}

resting value of $6.3 \mathrm{vol}$ per $100 \mathrm{ml}$ to $12.2 \mathrm{vol}$ per $100 \mathrm{ml}$. The response to exercise, however, was less than normal (23) in all and severely impaired in nine patients.

During exercise the heart rate of the patient with congenital heart block increased from 39 to 53. In this patient the increase in the cardiac output was proportional to the change in rate, and the stroke volume remained the same. Only two patients (Patients 2 and 4 ) with acquired heart block showed an increase in heart rate of a similar magnitude, and in these, the cardiac output increased despite a decrease in stroke volume. Among the remaining patients, the greatest increase in heart rate during exercise was 5 beats per minute. Despite the relative constancy of the heart rate all except one (Patient 8 ) of these patients developed some increase in the cardiac output during exercise, and this was achieved by an increase in stroke volume. The average stroke volume rose from $65 \mathrm{ml}$ per $\mathrm{m}^{2}$ to $78 \mathrm{ml}$ per $\mathrm{m}^{2}$ $(t=3.36, \mathrm{p}<0.01)$.

There was a slight increase in the average brachial arterial mean and systolic pressures, no change in the diastolic pressure, and a slight widening of the pulse pressure. The average pulmonary arterial mean pressure increased by 12 $\mathrm{mm} \mathrm{Hg}$, and the pulmonary wedge pressure by $8 \mathrm{~mm} \mathrm{Hg}$. The pulmonary vascular resistance did not change significantly. The pulmonary ar- terial and wedge pressures were both significantly greater $(t=5.23,5.01, \mathrm{p}<0.001)$ than the values observed in normal subjects studied in this laboratory and higher than the average values recorded in normal old men (21). Pulmonary ventilation during exercise was normal with respect to oxygen uptake (24) except for Patient 6, who was in heart failure.

The patient with congenital heart block had a normal cardiac output at rest and was able to perform more strenuous work than the others. He had the greatest increase in cardiac output and heart rate during exercise although the response was still less than normal. The pulmonary arterial and wedge pressures were abnormally high, both at rest and during exercise.

Exercise at electrically stimulated rates. The patients were able to perform more work, as judged by the oxygen uptake, during exercise at an average electrically stimulated rate of 79 beats per minute than at the idioventricular rate. In each patient there was a significant rise in cardiac output from rest to exercise at a heart rate in the range of 73 to 94 beats per minute. The average cardiac output increased from the resting value of $2.9 \mathrm{~L}$ per minute per $\mathrm{m}^{2}$ to $4.0 \mathrm{~L}$ per minute per $\mathrm{m}^{2}$ $(t=6.46, \mathrm{p}<0.001)$. The response of the cardiac output was still abnormal (Figure 3 ), but had improved in every patient except the one with congenital heart block, in whom it remained un- 
TABLE III

Mean values for cardiac output, intravascular pressures, and related measures at rest and during exercise at various heart rates in patients with complete heart block

\begin{tabular}{|c|c|c|c|c|c|c|c|c|c|c|c|c|}
\hline & \multicolumn{8}{|c|}{ Rest } & \multicolumn{4}{|c|}{ Exercise } \\
\hline & \multicolumn{2}{|c|}{ I.V.R.* } & \multicolumn{2}{|c|}{50 to 65} & \multicolumn{2}{|c|}{70 to 83} & \multicolumn{2}{|c|}{85 to 100} & \multicolumn{2}{|c|}{ I.V.R. } & \multicolumn{2}{|c|}{ E.S.R.† } \\
\hline Rate, beats/min & \multicolumn{2}{|r|}{35} & \multicolumn{2}{|c|}{55} & \multicolumn{2}{|c|}{77} & \multicolumn{2}{|c|}{92} & \multicolumn{2}{|c|}{39} & \multicolumn{2}{|r|}{79} \\
\hline Oxygen uptake, $\mathrm{ml} / \mathrm{min} / \mathrm{m}^{2}$ & 133 & $(20.8) \ddagger$ & 145 & $(23.3)$ & 151 & (19.3) & 147 & $(20.2)$ & 354 & $(82.5)$ & 415 & $(112.2)$ \\
\hline Pulmonary ventilation, $\mathrm{L} / \mathrm{min} / \mathrm{m}^{2}$ & 4.6 & $(1.3)$ & 4.6 & $(1.2)$ & 4.5 & $(1.0)$ & 4.4 & $(1.0)$ & 11.3 & $(3.2)$ & 11.9 & $(4.9)$ \\
\hline Respiratory exchange ratio & 0.79 & $(0.06)$ & 0.79 & $(0.08)$ & 0.79 & $(0.06)$ & 0.78 & $(0.04)$ & 0.84 & $(0.06)$ & 0.85 & $(0.06)$ \\
\hline A-v oxygen difference, vol/100 ml & 6.3 & (1.6) & 5.9 & (1.6) & 5.4 & $(1.2)$ & 5.4 & $(1.3)$ & 12.2 & $(2.0)$ & 10.8 & $(2.9)$ \\
\hline Cardiac output, $L / \mathrm{min} / \mathrm{m}^{2}$ & 2.2 & $(0.66)$ & 2.6 & $(0.74)$ & 2.9 & $(0.73)$ & 2.8 & $(0.73)$ & 3.0 & $(0.79)$ & 4.0 & $(0.87)$ \\
\hline Stroke volume, $m l / m^{2}$ & 65 & $(20.4)$ & 47 & (11.9) & 39 & $(9.9)$ & 31 & $(8.3)$ & 78 & $(14.5)$ & 51 & $(12.4)$ \\
\hline Brachial arterial pressure, $m m \mathrm{Hg}$ S§ & 204 & $(29.3)$ & 209 & $(23.0)$ & 204 & $(22.4)$ & 206 & $(25.5)$ & 232 & $(30.7)$ & 226 & $(27.6)$ \\
\hline D & 85 & $(12.1)$ & 105 & $(10.8)$ & 116 & (12.4) & 122 & $(16.6)$ & 84 & $(10.4)$ & 109 & $(18.3)$ \\
\hline M & 129 & $(20.5)$ & 147 & (15.6) & 155 & $(17.5)$ & 159 & $(21.1)$ & 140 & $(23.6)$ & 158 & $(25.0)$ \\
\hline \multirow{3}{*}{$\begin{array}{l}\text { Pulmonary arterial pressure, } \\
\qquad m m \mathrm{Hg}\end{array}$} & 48 & $(7.9)$ & 44 & $(7.4)$ & 42 & $(5.8)$ & 43 & $(5.7)$ & 67 & $(9.8)$ & 61 & (15.4) \\
\hline & 18 & $(4.6)$ & 19 & $(4.1)$ & 21 & $(4.3)$ & 23 & (4.6) & 25 & $(5.7)$ & 28 & $(10.1)$ \\
\hline & 29 & $(5.2)$ & 30 & $(5.7)$ & 31 & $(5.0)$ & 33 & $(3.8)$ & 41 & $(7.0)$ & 42 & $(11.7)$ \\
\hline Pulmonary wedge pressure, $\mathrm{mm} \mathrm{Hg}$ & 21 & $(4.8)$ & 20 & $(4.5)$ & 21 & $(5.6)$ & 21 & $(5.8)$ & 29 & $(4.8)$ & 28 & $(10.7)$ \\
\hline Pulmonary vascular resistance, dyne-sec- $\mathrm{cm}^{-5}$ & 180 & (106) & 176 & $(77)$ & 181 & $(63.5)$ & 198 & $(46.5)$ & 202 & (91.8) & 183 & $(89.3)$ \\
\hline
\end{tabular}

* I.V.R. = idioventricular rhythm.

$\dagger$ E.S.R. = electrically stimulated rate.

$\$$ The figures in parentheses are standard deviations.

$\$ \mathrm{~S}=$ systolic; $\mathrm{D}=$ diastolic; $\mathrm{M}=$ mean.

changed. In Patients 3 and 7 the response to exercise was restored to normal. Since the average oxygen uptake during exercise was greater under electrical stimulation than at idioventricular rate, the levels of cardiac output achieved under these two circumstances cannot be directly compared. This subject has been considered in detail elsewhere (23). We prefer to present the data as shown in Figure 3, where it is apparent that the effect of electrical stimulation is to bring the relationship between cardiac output and oxygen uptake during exercise closer to the normal expectation. An alternative way of analyzing these results is to calculate the increase in cardiac output per $100 \mathrm{ml}$ increase in oxygen uptake during exercise. For the patients with acquired heart block this figure averaged $0.29 \mathrm{~L}$ per minute per $\mathrm{m}^{2}$ at idioventricular rate and $0.43 \mathrm{I}$, per minute per $\mathrm{m}^{2}$

TABI,E, IV

Physical characteristics, cardiac output, intravascular pressures, and related measurements in 77 normal subjects ( 45 men, 32 women), at rest in supine position

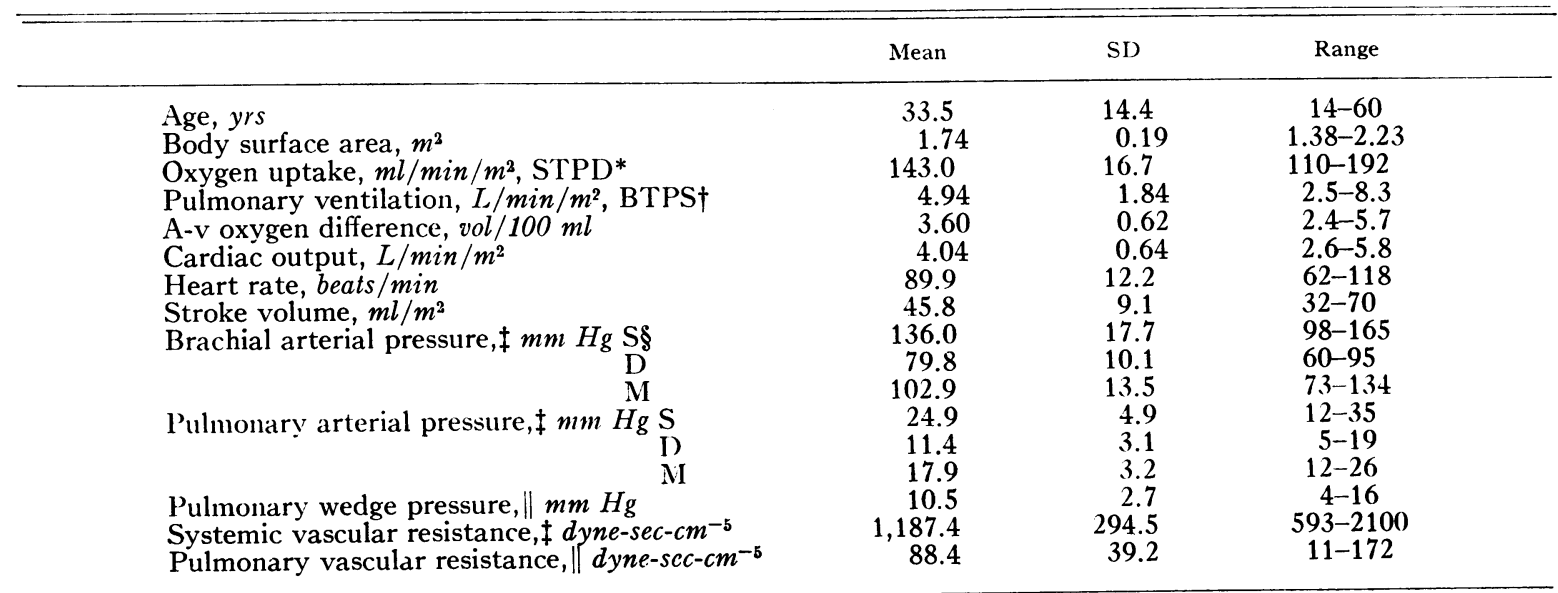

* STPD $=$ Standard temperature, pressure, dry.

+ BTPS = Body temperature, pressure, saturated with water.

$\ddagger 67$ subjects.

$\$ \mathrm{~S}=$ systolic; $\mathrm{D}=$ diastolic; $\mathrm{M}=$ mean.

51 subjects. 
TABLE V

Individual values for cardiac output, oxygen uptake, heart rate, and intravascular pressures during exercise at idioventricular rate in patients with complete heart block

\begin{tabular}{|c|c|c|c|c|c|c|c|c|c|c|}
\hline \multirow[b]{3}{*}{ Patient } & \multirow{3}{*}{$\begin{array}{c}\text { Heart } \\
\text { rate }\end{array}$} & \multirow{3}{*}{$\begin{array}{l}\text { Oxygen } \\
\text { uptake }\end{array}$} & \multirow{3}{*}{$\begin{array}{l}\text { Cardiac } \\
\text { output }\end{array}$} & \multicolumn{7}{|c|}{ Pressure } \\
\hline & & & & \multicolumn{3}{|c|}{ Brachial arterial } & \multicolumn{3}{|c|}{ Pulmonary arterial } & \multirow{2}{*}{$\begin{array}{c}\text { Pulmonary } \\
\text { wedge } \\
\mathbf{M}\end{array}$} \\
\hline & & & & $\mathrm{S}^{*}$ & $\mathrm{D}$ & $\bar{M}$ & $\mathbf{S}$ & $\mathrm{D}$ & $\bar{M}$ & \\
\hline & beats/min & $m l / m i n / m^{2}$ & $L / \min / m^{2}$ & & & & $n \mathrm{Hg}$ & & & \\
\hline 1 & 53 & 557 & 5.1 & 200 & 83 & 122 & 52 & 15 & 32 & 24 \\
\hline 2 & 43 & 297 & 3.6 & 225 & 78 & 122 & 56 & 20 & 34 & 26 \\
\hline 3 & 43 & 375 & 3.2 & 214 & 72 & 133 & 74 & 27 & 43 & 33 \\
\hline 4 & 38 & 428 & 2.9 & 265 & 97 & 181 & 74 & 24 & 46 & 32 \\
\hline 5 & 31 & 290 & 2.2 & 221 & 66 & 139 & 66 & 24 & 43 & 31 \\
\hline 6 & 38 & 390 & 2.9 & 270 & 99 & 188 & 88 & 39 & 49 & 40 \\
\hline 7 & 31 & 331 & 3.1 & 214 & 79 & 117 & 55 & 22 & 35 & 31 \\
\hline 8 & 44 & 323 & 2.3 & 218 & 92 & 135 & 65 & 28 & 40 & 27 \\
\hline 9 & 41 & 233 & 2.3 & 207 & 80 & 125 & 64 & 23 & 39 & 29 \\
\hline 10 & 39 & 344 & 3.0 & 251 & 92 & 149 & 69 & 24 & 37 & 17 \\
\hline 11 & 26 & 306 & 2.4 & 295 & 95 & 150 & 66 & 27 & 40 & 26 \\
\hline 12 & 35 & 379 & 2.8 & 203 & 81 & 118 & 70 & 27 & 40 & 31 \\
\hline
\end{tabular}

* $\mathrm{S}=$ systolic $; \mathrm{D}=$ diastolic $; \mathrm{M}=$ mean.

at electrically stimulated rate. The difference between these two figures was significant $(t=2.58$, $\mathrm{p}<0.02)$.

Since the heart rate under artificial stimulation remained unchanged during exercise, the rise in cardiac output was achieved by an increase in stroke volume. The mean stroke volume increased from 39 to $51 \mathrm{ml}$ per $\mathrm{m}^{2}$, which was significant $(t=4.98, \mathrm{p}<0.001)$.

Pulmonary ventilation during exercise remained normal with respect to oxygen uptake (24).

The changes in systemic arterial, pulmonary arterial, and wedge pressures were similar to those observed when the patients exercised at idioventricular rhythm (Table III).

\section{Discussion}

The cardiac output in the patients with acquired complete heart block was less than normal, even allowing for their advanced age. The stroke volume was larger than normal, but this increase was insufficient to maintain a normal cardiac output in the face of the extreme bradycardia. The low cardiac output appears to have been due to a combination of the simple effects of bradycardia

TABLE VI

Individual values for cardiac output, oxygen uptake, heart rate, and intravascular pressures during exercise at electrically stimulated heart rates in patients with complete heart block

\begin{tabular}{|c|c|c|c|c|c|c|c|c|c|c|}
\hline \multirow[b]{3}{*}{ Patient } & \multirow{3}{*}{$\begin{array}{c}\text { Heart } \\
\text { rate }\end{array}$} & \multirow{3}{*}{$\begin{array}{c}\text { Oxygen } \\
\text { uptake }\end{array}$} & \multirow{3}{*}{$\begin{array}{l}\text { Cardiac } \\
\text { ouptut }\end{array}$} & \multicolumn{7}{|c|}{ Pressure } \\
\hline & & & & \multicolumn{3}{|c|}{ Brachial arterial } & \multicolumn{3}{|c|}{ Pulmonary arterial } & \multirow{2}{*}{$\begin{array}{c}\text { Pulmonary } \\
\text { wedge } \\
\text { M }\end{array}$} \\
\hline & & & & $\mathrm{S}^{*}$ & D & $\mathbf{M}$ & $\bar{S}$ & $\mathrm{D}$ & $\overline{\mathbf{M}}$ & \\
\hline & beats/min & $\mathrm{ml} / \mathrm{min} / \mathrm{m}^{2}$ & $L / \mathrm{min} / \mathrm{m}^{2}$ & & & & $\mathrm{Hg}$ & & & \\
\hline 1 & 79 & 555 & 5.1 & 203 & 104 & 136 & 38 & 18 & 28 & 18 \\
\hline 2 & 75 & 318 & 4.6 & 215 & 96 & 142 & 49 & 17 & 31 & 27 \\
\hline 3 & 73 & 598 & 5.7 & 223 & 90 & 144 & 77 & 38 & 57 & 46 \\
\hline 4 & 77 & 580 & 3.7 & 257 & 123 & 187 & 61 & 26 & 42 & 26 \\
\hline 5 & 74 & 336 & 3.6 & 215 & 86 & 140 & 48 & 16 & 30 & 12 \\
\hline 6 & 78 & 505 & 3.8 & 268 & 132 & 202 & 86 & 46 & 62 & 46 \\
\hline 7 & 76 & 383 & 5.0 & 191 & 88 & 128 & 37 & 15 & 26 & 15 \\
\hline 8 & 80 & 341 & 2.9 & 219 & 111 & 152 & 64 & 34 & 47 & 31 \\
\hline 9 & 94 & 286 & 3.7 & 210 & 116 & 160 & 70 & 37 & 52 & 27 \\
\hline 10 & 77 & 337 & 3.7 & 238 & 114 & 176 & 65 & 24 & 39 & 21 \\
\hline 11 & 78 & 346 & 3.0 & 276 & 146 & 193 & 61 & 29 & 43 & 31 \\
\hline 12 & 82 & 394 & 3.5 & 200 & 107 & 139 & 75 & 33 & 48 & 32 \\
\hline
\end{tabular}

$* \mathrm{~S}=$ systolic $; \mathrm{D}=$ diastolic $; \mathrm{M}=$ mean. 
and a degree of impaired contractility of the myocardium. Impaired contractility might be expected to be associated with ischemic lesions in the myocardium, but to some extent it may also be a physiological function of bradycardia itself (2527). The influence of bradycardia alone, or of bradycardia plus the physiological "staircase effect," may be deduced from the fact that the cardiac output could be restored to normal by increasing the rate. Yet, even under these circumstances, the wedge pressure remained abnormally high, which would suggest that the normal cardiac output was only achieved in the presence of an increased left ventricular filling pressure.

The high wedge pressure may itself have been due to a specific impairment of the contractility of the left ventricle. However, the fact that the highest wedge pressure was observed in the two patients with overt congestive cardiac failure suggests that hypervolemia may also have been an important factor. The elevation of the wedge pressure was not due to the bradycardia alone, since the pressure remained unchanged while the heart rate increased. This constancy of the wedge pressure contrasts with observations made in patients with mitral stenosis (28). The relationship between heart rate and mean wedge pressure would, in any case, be expected to be a complex one because of the presumably nonlinear distensibility of the cardiac chambers, the inconstancy of the resistance of the mitral valve, and the variable rate of the flow of blood into the ventricle.

The abnormally high pulmonary arterial pressure appears to be due to the raised wedge pressure. Although the pulmonary vascular resistance was higher than would be normal in younger people, this could be entirely due to age. There are no direct measurements of the pulmonary vascular resistance in normal elderly people, but the observations that the cardiac output is reduced $(20,21)$ while the pulmonary arterial and wedge pressures remain the same as in young people suggest that the resistance rises with age.

At idioventricular rate the response of the cardiac output to exercise was severely impaired. In the normal subject exercising in the supine position the increase in cardiac output is largely due to the increase in heart rate, stroke volume increasing but little (29). An impaired response was therefore to be expected in these patients, since the heart rate did not increase appreciably during exercise. A simliar but less severe impairment of response has been observed when the normal increase in heart rate during exercise is prevented by the administration of pronethalol to supine normal subjects (30). The small increase in cardiac output that did occur was due to a rise in stroke volume, the extent of the increase being similar to that seen in normal subjects.

When the heart rate during exercise was increased by electrical stimulation, the response of cardiac output was improved, and it became normal in some patients. Although this supports the view that bradycardia was an important reason for the impaired response at idioventricular rate, it is necessary to consider why the cardiac output response was usually still abnormal at faster electrically stimulated rates. One explanation is that the heart rate, although much faster than the idioventricular rate, was still less than would have occurred in normal subjects performing sinilar exercise. The heart rate of young subjects under these conditions ranged from 87 to 115 beats per minute (24), and that of normal older subjects would have been greater. The mean electrically stimulated rate of 79 beats per minute (range, 73 to 94 ) probably did not allow cardiac output to rise to levels it would have reached at more normal heart rates. Impaired myocardial contractility may have played some part in the inadequate response, especially in view of the high wedge pressure. Finally, since the heart was very large in some of the patients, functional tricuspid incompetence may have contributed to the impaired response of the cardiac output as suggested by McMichael and Shillingford (31).

The resting oxygen uptake, which was normal at idioventricular rates, increased significantly as the heart rate was increased. The pulmonary ventilation and respiratory exchange ratio remained unaltered, and the patients were in a steady respiratory and cardiac state. The heart was the only organ whose requirement seems certain to have increased, although the myocardial oxygen uptake has not been measured in such patients, nor its variation with heart rate at rest.

There is considerable evidence from experiments in animals that myocardial oxygen con- 
sumption is a function of heart rate and systolic blood pressure $(32,33)$. In normal subjects the myocardial oxygen uptake is about $16 \mathrm{ml}$ per minute per $\mathrm{m}^{2}$, which is approximately equal to the increase of total oxygen uptake at electrically stimulated rate in the patients with heart block. The present findings are, therefore, consistent with the suggestion that a twofold increase in heart rate doubled the myocardial oxygen uptake.

There was a range of heart rates at which cardiac output reached a maximum, further increases in rate often being associated with a decrease in cardiac output. This optimal rate lay between 70 and 83 beats per minute, and at these rates the patients felt most comfortable. They were also able to exercise more readily, since they were not troubled by the symptoms of weakness and fatigue that were experienced at idioventricular rates. Possibly, however, they would have noted further improvement, and cardiac output during exercise would have been closer to normality at faster heart rates than were used in this study. Breathlessness was not a complaint in these patients, providing further evidence that this symptom is determined by factors other than the cardiac output.

The findings in patients with acquired heart block differ in some respects from those previously reported for patients with congenital heart block (3-6), in whom the heart rate tends to be faster and less fixed. Others have reported that in patients with congenital heart block the cardiac output is normal and responds normally to exercise, and that pressures in the pulmonary circulation are also normal (6). In the one patient with congenital heart block in the present study, however, the cardiac output although normal at rest did not respond normally to exercise, and the pulmonary wedge pressure was elevated.

\section{Summary}

Fourteen patients with complete heart block (13 acquired and 1 congenital) were studied at rest and during exercise in the supine position, both at idioventricular and various electrically stimulated heart rates.

Cardiac otput at rest was abnormally low, despite an increased stroke volume, and the response of cardiac output to exercise was greatly impaired.
Pulmonary arterial and wedge pressures were abnormally high at rest and during exercise.

At faster, electrically stimulated rates, the cardiac output at rest rose to normal levels, and there was an improvement in the response of cardiac output to exercise. The optimal rate at rest usually lay between 70 and 83 beats per minute.

The resting oxygen uptake was normal at idioventricular rates but increased significantly when the heart rate rose.

The hemodynamic abnormalities in these patients appear to be due to a combination of bradycardia and impaired myocardial contractility.

\section{Acknowledgments}

We thank Mr. A. C. Pincock, Mrs. Anne Hollyhock, Mrs. Pauline Furness, Miss Susan Pepper, Miss Geraldine Gerrard, and Staff Nurse Margaret Booth for their technical assistance.

Most of the patients were under the care of Dr. A. B. Taylor and Mr. L. D. Abrams. Mr. R. Lightwood designed and built the cardiac pacemakers and advised us about their use. Dr. T. J. Bayley assisted in some of the studies. To all of these colleagues and others who have helped us during these investigations we offer our thanks.

\section{References}

1. Liljestrand, G., and E. Zander. Studies of the work of the heart during rest and muscular activity in a case of uncomplicated total heart-block. Acta med. scand. 1927, 66, 501.

2. Alt, H. L., G. L. Walker, and W. C. Smith. The cardiac output in heart disease II. Effect of exercise on the circulation in patients with chronic rheumatic valvular disease, subacute rheumatic fever and complete heart block. Arch. intern Med. 1930, 45, 958.

3. Lagerlöf, H., and L. Werkö. Studies on circulation in man. III. The auricular pressure pulse. Cardiologia (Basel) 1948, 13, 241.

4. Paul, M. H., A. M. Rudolph, P. A. Ongley, and A. S. Nadas. Congenital complete atrioventricular block: a hemodynamic and clinical study (abstract). Circulation 1956, 14, 981.

5. Kelly, H. G., and R. I. S. Bayliss. Influence of heart-rate on cardiac output. Studies with digoxin and atropine. Lancet 1949, 2, 1071.

6. Holmgren, A., P. Karlberg, and B. Pernow. Circulatory adaptation at rest and during muscular work in patients with complete heart block. Acta med. scand. 1959, 164, 119.

7. Landegren, J., and G. Biörck. The clinical assessment and treatment of complete heart block and Adams-Stokes attacks. Medicine (Baltimore) 1963, 42, 171. 
8. Gilchrist, A. R. The effects of bodily rest, muscular activity and induced pyrexia on the ventricular rate in complete heart-block. Quart. J. Med. 1934, 3, 381.

9. Bellet, S. Mechanism and treatment of A-V heart block and Adam-Stokes syndrome. Progr. cardiovasc. Dis. 1960, 2, 691.

10. Abrams, L. D., W. A. Hudson, and R. Lightwood. A surgical approach to the management of heartblock using an inductive coupled artificial cardiac pacemaker. Lancet 1960, 1, 1372.

11. Hudson, W. A., and N. Segel. Haemodynamic effects of artificial cardiac pacemaking in patients with complete heart block. Thorax 1962, 17, 180.

12. Zoll, P. M. Resuscitation of the heart in ventricular standstill by external electric stimulation. New Engl. J. Med. 1952, 247, 768.

13. Leatham, A., P. Cook, and J. G. Davies. External electric stimulator for treatment of ventricular standstill. Lancet 1956, 2, 1185.

14. Weirich, W. L., M. Paneth, V. L. Gott, and C. W. Lillehei. Control of complete heart block by use of an artificial pacemaker and a myocardial electrode. Circulat. Res. 1958, 6, 410.

15. Furman, S., and G. Robinson. The use of an intracardiac pacemaker in the correction of total heart block. Surg. Forum 1958, 9, 245.

16. Escher, D. J. W., J. B. Schwedel, R. Eisenberg, C. Gitsios, N. Perna, and A. Jamshidi. Cardiovascular dynamic responses to artificial pacing of patients in heart block (abstract). Circulation 1961, 24, 928.

17. Bevegård, S. Observations on the effect of varying ventricular rate on the circulation at rest and during exercise in two patients with an artificial pacemaker. Acta med. scand. 1962, 172, 615.

18. Wade, O. L., J. M. Bishop, G. Cumming, and K. W. Donald. A method for the rapid estimation of the percentage oxygen saturation and oxygen content of blood. Brit. med. J. 1953, 2, 902.

19. Dexter, L., J. W. Dow, F. W. Haynes, J. L. Whittenberger, B. G. Ferris, W. T. Goodale, and H. K. Hellems. Studies of the pulmonary circulation in man at rest. Normal variations and the interrelations between increased pulmonary blood flow, elevated pulmonary arterial pressure and high pulmonary "capillary" pressures. J. clin. Invest. 1950, 29, 602.

20. Brandfonbrener, M., M. Landowne, and N. W. Shock. Changes in cardiac output with age. Circulation 1955, 12, 557.
21. Granath, A., B. Jonsson, and T. Strandell. Studies on the central circulation at rest and during exercise in the supine and sitting body position in old men. Preliminary report. Acta med. scand. 1961, 169, 125.

22. Bishop, J. M., K. W. Donald, and O. L. Wade. Circulatory dynamics at rest and on exercise in the hyperkinetic states. Clin. Sci. 1955, 14, 329.

23. Wade, O. L., and J. M. Bishop. Cardiac Output and Regional Blood Flow. Oxford, Blackwell Scientific Publications, 1962, pp. 51-72.

24. Donald, K. W., J. M. Bishop, G. Cumming, and O. L. Wade. The effect of exercise on the cardiac output and circulatory dynamics of normal subjects. Clin. Sci. 1955, 14, 37.

25. Bowditch, H. P. Über die Eigenthümlichkeiten der Reizarkeit, welche die Muskelfasern des Herzens zeigen. Ber. Königl. Sächs. Ges. Wissen. 1871, 23, 652 .

26. Dale, A. S. The relation between amplitude of contraction and rate of rhythm in the mammalian ventricle. (Including interpretation of the apparent indirect action of the vagus on amplitude of ventricular contraction). J. Physiol. (Lond.) 1930, 70, 455.

27. Sarnoff, S. J., J. H. Mitchell, M. S. Gilmore, and J. P. Remensnyder. Homeometric autoregulation in the heart. Circulat. Res. 1960, 8, 1077.

28. Gorlin, R., B. M. Lewis, F. W. Haynes, R. J. Spiegl, and L. Dexter. Factors regulating pulmonary "capillary" pressure in mitral stenosis. IV. Amer. Heart J. 1951, 41, 834.

29. Wade, O. L., and J. M. Bishop. Cardiac Output and Regional Blood Flow. Oxford, Blackwell Scientific Publications, 1962, pp. 65-69.

30. Bishop, J. M., and N. Segel. The circulatory effects of intravenous pronethalol in man, at rest and during exercise in the supine and upright positions. J. Physiol. (Lond.) 1963, 169, 112P.

31. McMichael, J., and J. P. Shillingford. The role of valvular incompetence in heart failure. Brit. med. J. 1957, 1, 537.

32. Laurent, D., C. Bolene-Williams, F. L. Williams, and L. N. Katz. Effects of heart rate on coronary flow and cardiac oxygen consumption. Amer. J. Physiol. 1956, 185, 355.

33. Berglund, E., H. G. Borst, F. Duff, and G. L. Schreiner. Effect of heart rate on cardiac work, myocardial oxygen consumption and coronary blood flow in the dog. Acta physiol. scand. 1958, 42, 185. 